\title{
Constructal design of evacuation from a three-dimensional living space
}

\author{
C.H. Lui ${ }^{\text {a }}$, N.K. Fong ${ }^{\mathrm{a}}$, S. Lorente $^{\mathrm{b}}$, A. Bejan ${ }^{\mathrm{c}, *}$, W.K. Chow ${ }^{\mathrm{a}}$ \\ ${ }^{a}$ The Hong Kong Polytechnic University, Department of Building Services Engineering, Hong Kong, China \\ ${ }^{\mathrm{b}}$ University of Toulouse, INSA, 135 Avenue de Rangueil, 31077 Toulouse, France \\ ${ }^{\mathrm{c}}$ Duke University, Department of Mechanical Engineering and Materials Science, Durham, NC 27708-0300, USA
}

\section{H I G H L I G H T S}

- The fundamental relation between the configuration of a building and the evacuation time needed by all the inhabitants.

- Evacuation of inhabitants is treated as a physical flow system.

- The optimal floor shape and profile shape are reported.

- The theoretical predictions are validated by extensive numerical simulations of pedestrian flow.

\section{A R T I C L E I N F O}

\section{Article history:}

Received 5 August 2014

Received in revised form 14 November

2014

Available online 12 December 2014

\section{Keywords:}

Constructal law

Evacuation

Pedestrian movement

Urban design

Safety

Architecture

\begin{abstract}
A B S T R A C T
This paper demonstrates the fundamental relation that exists between the configuration of a three-dimensional living space and the time needed for the evacuation of all the inhabitants. The evacuation is treated as a physical flow system consisting of pedestrians who move from a volume to one or two exits. The living space has two variable aspect ratios, the floor shape and the profile shape (or the number of floors). First, the paper reports analytically the optimal floor and profile shapes for which the total evacuation time is minimum. Second, the analytical results are complemented and validated by numerical results obtained based on numerous simulations of pedestrian flow from volume to exits. The numerical results are further validated by performing the simulations of pedestrian movement with two different computational codes (Simulex and FDS + Evac). The fundamental relation presented in this paper can be used in the design of larger and more complex living spaces in modern urban settings.
\end{abstract}

(c) 2014 Elsevier B.V. All rights reserved.

\section{Introduction}

Self-organization is the backbone of phenomena of design in nature, and it covers the range from geophysics to biology, from inanimate to animate flow systems. Reviews of the current literature show that this part of physics is covered by the constructal law [1,2], which accounts for the natural tendency toward evolutionary design over time (organization, configuration, architecture) that provides greater and easier access in all flow systems that are free to morph.

The evolutionary design tendency is most familiar to us in the flow systems that surround and connect us: transportation, crowd dynamics, business, economics and government. The flow designs that will rule urban design as population density

\footnotetext{
* Corresponding author. Tel.: +1 9196605309.

E-mail address: abejan@duke.edu (A. Bejan).
} 
continues to increase is crowd movement [1-10], the practical aspect of which is urban design [11-13] and crowd evacuation [14-19]. Urban design expands not only inward, toward high density, but also vertically, above and below ground.

Crowd evacuation is a major concern in a future with "sustainability", and, as in Refs. [1-11], in the present paper we treat it as physics. We rely on the constructal law in order to discover the most basic features of a three-dimensional living space (edifice above ground, or underground, e.g., subway station) such that all the inhabitants find easiest access to the outside in case of emergency.

The usual method for the search of building architectures that offer faster evacuation during emergency is based on voluminous numerical simulations of randomly moving pedestrians who pursue the same goal, which is to escape. This paper demonstrates that the search is accelerated significantly when it is based on the method of constructal design, which consists of discovering the fundamental relationship between global flow access and organization-the system configuration when the configuration morphs freely. The present paper identifies analytically the main geometric features of the three dimensional space that offers the shortest evacuation time for all the people present at the start of the emergency. The main features are the floor aspect ratio, and the aspect ratio of the vertical profile of the building. These two features are confirmed based on extensive numerical simulations of pedestrian evacuation, by using two different numerical packages, FDS and Simulex.

The literature on emergency evacuation [19] is extensive and illustrates the critical importance of developing a fundamental basis for designs that facilitate evacuation. For example, the flow of pedestrians based on the size and shape of occupants, queuing in enclosures, flow speed, and passage width was studied by Fruin [16]. Studies focused on keeping pedestrians speeds and directions related to each other in moving along stairways and across horizontal surfaces.

Effective width by including the edge influence of the walkways was suggested for design [20]. The effective width must be reduced by $0.46 \mathrm{~m}$ on each side for corridors based on the field survey. The edge effect depends on the activities of the individuals and types of enclosures. However, this concept was not applied to stair movement because more variables are involved. Estimation for vertical movement would be more complicated than that along horizontal surfaces. Speeds attained by occupants depend on the physical dimensions of the stairway, such as stairway angle, tread depth, riser heights, and handrails. Occupant movement would be slower in an enclosed stairwell because the population density changes along the way to give rise to bottlenecks and blockages.

Systematic and detailed observations of evacuation drills in tall buildings were reported in the literature [21-25]. The concept of "edge gap" was further extended to develop an effective width model [22,24]. Taking into account the human propensity to maintain a separation from stationary objects and walls, calculations based only on the "unit width" alone are not accurate if the crowd density is not high. The same conclusion applies to staircase movement. The speed down the stairs is related to the crowd density. Field studies on stairs flow rates in 29 drills in tall buildings $[22,24]$ suggested that the edge effect was $0.3 \mathrm{~m}$. A speed-density relation in uncontrolled total evacuations of tall office buildings was deduced by Pauls [21].

Useful for design are the results reported by Polus et al. [22] and Ando et al. [23]. One- and three-regime speed-density models for the pedestrian traffic were developed [22] based on survey studies in the central business district of Haifa. The walking speed of the pedestrian was found to decrease significantly with increasing density, and the walking speeds of men were significantly greater than the speeds of women. Based on the analysis of speed and density, four levels of services for pedestrians were defined and reported. Organized crowd movement is a common feature in dense railway stations [23], and it was documented with video recordings. Passengers did not know that their movements were recorded. Walking speeds were confirmed to depend on crowd density as proposed by Predtechenskii and Milinskii [26]. The relationship between speed and density, both on a level surface and up and down flights of stairs was also presented. Results were converted into volume flow rates by Smith [24] for convenience in justifying the flow rates along passageways, up and down stairs, and through gates.

Pedestrian speed/flow curves were worked out for six main features encountered in the underground system by Annesley et al. [25]. Investigated were passageways, stairways, escalators, concourses, junctions of passageways, and the platform. Based on the data collected from the survey at a number of locations in the London Underground, the curves were improved by Daly et al. [27] for better estimating pedestrian flow and travel times under congested conditions.

Correlations of velocity for mobile individuals were proposed by Nelson and Mowrer [28] by reviewing the results reported in the literature. A model on the movement of individual occupants was developed by Thompson and Marchant [15] based on the inter-personal distance (not on occupant density). The result was derived by analyzing videos of crowd movement. The inter-personal distance is a measure of distance between the center points of the bodies of two individuals. The relationship between the walking speed and inter-personal distance was presented. The median values were fitted from the surveyed data. The age-weighted values are based on a combination of the median values and the data quoted by Ando et al. [23] for normal, unimpeded walking speeds. The walking speed would decrease when the inter-person distance is less than a specific value, which becomes zero when the individuals are tightly packed. The inter-personal distance is equal to the body width. The interface threshold was suggested to be $1.6 \mathrm{~m}$. When the separation between individuals is greater than this value, their speed is not affected. The unimpeded walking speed was found to be around $1.7 \mathrm{~m} \mathrm{~s}^{-1}$ for men and $0.8 \mathrm{~m} \mathrm{~s}^{-1}$ for women.

Data on downstairs movement in three multiple occupancy buildings were reported by Proulx [29]. The stairway movement was found to involve several features of behavior such as resting and communication. Most of the occupants showed a comparable mean speed on the stairs during the emergency drills. Among all occupants, the travel speed was between 0.52 and $0.62 \mathrm{~m} \mathrm{~s}^{-1}$ on non-crowded stairs. Those older than 65 moved significantly slower, at $0.43 \mathrm{~m} \mathrm{~s}^{-1}$, and children between 


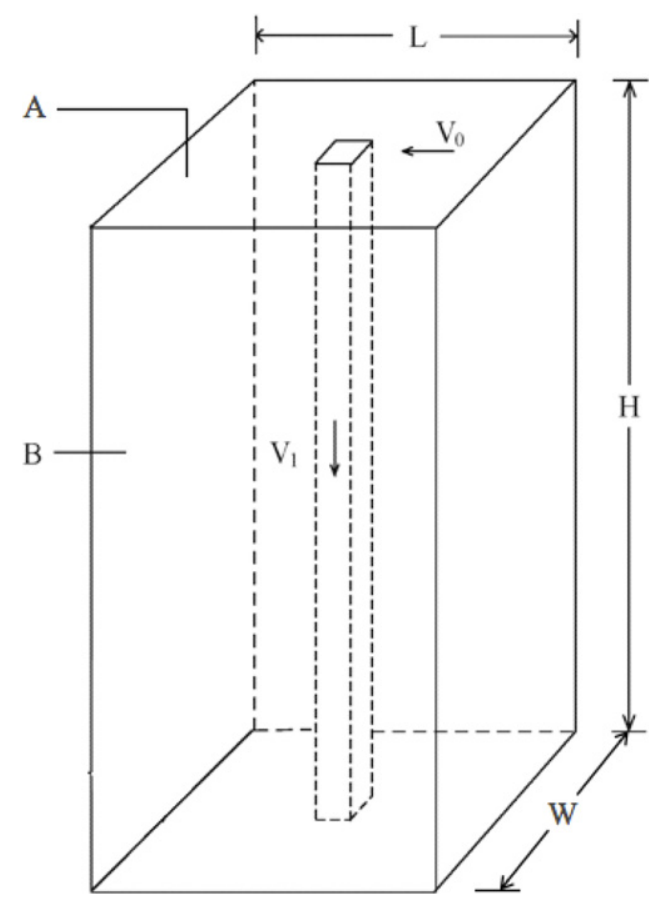

Fig. 1. Tall building with square floor areas and one central elevator.

the ages of 2 and 5 moved at a mean speed of $0.45 \mathrm{~m} \mathrm{~s}^{-1}$. Updated values were reported for sports fields [30] and transit systems [31].

In summary, evacuation depends on psychological, physiological, social, and environment factors. It is difficult to decide which study is more appropriate on estimating the evacuation time for exit design as the data are derived from field surveys. This is why in the present study we rely on the simplest possible description of pedestrian movement in order to determine the relationship between the architecture of the inhabited space and the time required for complete evacuation. We explore this relationship first theoretically and then numerically, based on computer simulations of crowd movement.

\section{Analysis}

Consider a large building of height $H$ and floor area $A=L \times W$, which is the same for all the floors (Fig. 1). The movement to and from $A$ is by riding on an elevator (or climbing on a staircase) located in the center of $A$, and by walking on $A$ along corridors the lengths of which are $L / 2$ and $W / 2$. The volume of the building is fixed,

$$
B=A H
$$

however, the shape is not. There are two speeds of movement, walking at speed $V_{0}$ horizontally on $A$, and riding vertically at speed $V_{1}$ on the elevator.

We seek to determine the building shape for which the evacuation time is minimum. The dimensions $H, L$ and $W$ vary subject to the volume constraint (1). Consequently, the shape of the building is represented by two degrees of freedom, the shape of the building elevation $H / A^{1 / 2}$, and the shape of the building plan, $W / L$. In this section we explore the two shaping opportunities independently. First, we fix $H / A^{1 / 2}$ and vary $W / L$ subject to fixed $A$ and $B$ (which also means that $H$ is fixed, $H=B / A$ ). Next, we fix the floor shape $W / L$ and vary the shape on the vertical, $H / A^{1 / 2}$ subject to constant volume.

The analysis consists of calculating the evacuation time needed by all the occupants, and minimizing it by varying the floor shape. Assume that the occupants are distributed uniformly over the two floors. The total evaluation time is ruled by the time needed by the person who is located the farthest from one of the exits. The farthest location is one of the corners of the upper floor. If the path from such a corner is a straight line, then the total time is

$$
t=\frac{1}{V_{0}}\left[\left(\frac{L}{2}\right)^{2}+\left(\frac{W}{2}\right)^{2}\right]^{1 / 2}+t_{1}+\frac{L / 2}{V_{0}}
$$

where the last term is the time needed to walk from the bottom of the staircase to one of the exits. The time $t_{1}=H / V_{1}$ is spent descending on the staircase, and it is fixed because $H$ is fixed. Because the floor area $A=L W$ is fixed, the total time $t$ is minimum when

$$
\frac{W}{L}=3^{1 / 2}
$$


which represents the design with $L=3^{-1 / 4} A^{1 / 2}, W=3^{1 / 4} A^{1 / 2}$ and

$$
t=\frac{3^{3 / 4} A^{1 / 2}}{2 V_{0}}+t_{1} .
$$

If, instead, the walk from the corner to the stairwell on the upper floor proceeds along two or more orthogonal corridors aligned with $L$ and $W$, the length of the walk is $L / 2+W / 2$, and the total evacuation time is

$$
t=\frac{1}{V_{0}}\left(\frac{L}{2}+\frac{W}{2}\right)+t_{1}+\frac{L / 2}{V_{0}} .
$$

This can be minimized subject to $A=L W$, constant, and the resulting design is $L=(A / 2)^{1 / 2}, W=(2 A)^{1 / 2}$, and

$$
\begin{aligned}
& \frac{W}{L}=2 \\
& t=\frac{2^{1 / 2} A^{1 / 2}}{V_{0}}+t_{1} .
\end{aligned}
$$

Note the similarity between Eqs. (4) and (7).

Next, we consider the second degree of freedom: the shape of the building when viewed from the side, $H / A^{1 / 2}$. For simplicity, we assume that the floor area is square, and Eq. (5) holds, with $A=L^{2}$. The time needed to descend from the top floor to ground level is $t_{1}=H / V_{1}$. From Eq. (5), the total evacuation time is

$$
t=\frac{3 A^{1 / 2}}{2 V_{0}}+\frac{H}{V_{1}} .
$$

Eliminating $H$ between Eqs. (1) and (8), we obtain

$$
t=\frac{3 L}{2 V_{0}}+\frac{B}{L^{2} V_{1}}
$$

which is minimized by selecting the floor length scale

$$
L=\left(B \frac{4 V_{0}}{3 V_{1}}\right)^{1 / 3} \text {. }
$$

The building shape, height and the minimum evacuation time that correspond to this design are

$$
\begin{aligned}
& H=B^{1 / 3}\left(\frac{3 V_{1}}{4 V_{0}}\right)^{2 / 3} \\
& \frac{H}{L}=\frac{B / L^{2}}{L}=\frac{3 V_{1}}{4 V_{0}} \\
& t_{\min }=\frac{3^{5 / 3}}{2^{4 / 3}}\left(\frac{B}{V_{0}^{2} V_{1}}\right)^{1 / 3} .
\end{aligned}
$$

The slenderness $H / L$ increases as the staircase and elevator designs evolve toward greater speeds $V_{1}$. The minimization of evacuation time requires the use of faster elevators in taller buildings, in accord with the proportionality (11).

If instead of the square-floor assumption we use the optimal shape for floors with diagonal access, $W / L=3^{1 / 2}$, then the minimization of the evacuation time $t$ of Eq. (4) leads to the following results,

$$
\begin{aligned}
& L=\left(\frac{4 B V_{0}}{3^{3 / 2} V_{1}}\right)^{1 / 3} \\
& H=3^{1 / 2} B^{1 / 3}\left(\frac{V_{1}}{4 V_{0}}\right)^{2 / 3} \\
& \frac{H}{L}=\frac{3}{4} \frac{V_{1}}{V_{0}}, \quad \frac{H}{W}=\frac{3^{1 / 2}}{4} \frac{V_{1}}{V_{0}} \\
& t_{\min }=\frac{3^{3 / 2}}{2^{4 / 3}}\left(\frac{B}{V_{0}^{2} V_{1}}\right)^{1 / 3} .
\end{aligned}
$$

These results are close to Eqs. (10)-(13).

\section{Numerical simulations}

In the second part of this study we investigated numerically the effect of flow configuration on pedestrian evacuation from the three-dimensional space of Fig. 1. As in the theoretical part (Section 2), we first fixed $H$ and varied $W / L$, and later 


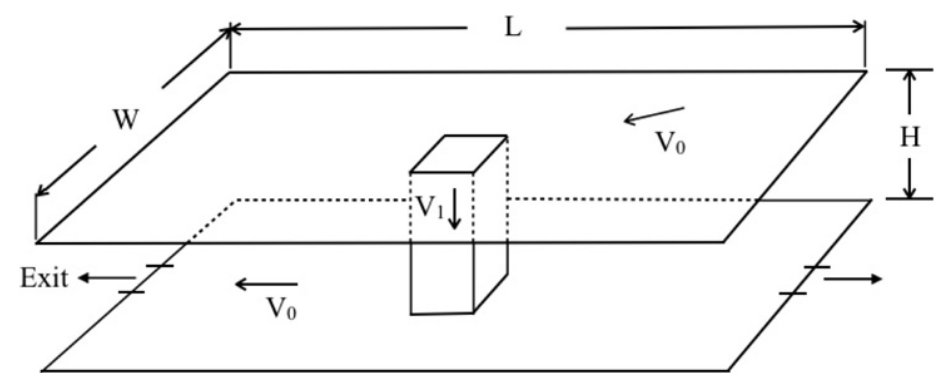

Fig. 2. Building with two floors, one connecting staircase, and two exits at ground level.

we fixed $W / L$ and varied $H$. We started with the simple configuration defined in Fig. 2: the building has two floors communicating through a staircase of height $H$, which is fixed. Each floor is a rectangular area of length $L$ and width $W$. The staircase is located either in the center of the floor area, or near one of the exits. There are two exits on the ground floor, located in the middle of each $W$ side.

The numerical simulations were conducted by assuming the fixed floor area $L W=900 \mathrm{~m}^{2}$, and allowing the shape of the area $W / L$ to vary. The square floor served as reference: see cases A-C in Table 1 . The staircase volume was a parallelepiped of height $H=3 \mathrm{~m}$ and square horizontal cross-section, $3 \mathrm{~m} \times 3 \mathrm{~m}$. Each exit was $3 \mathrm{~m}$ wide. The cases summarized in Table 1 differ with respect to floor dimensions $(L, W)$, staircase position, and initial number of people on the ground floor and the upper floor.

The initial density of pedestrians was set at one person per $9 \mathrm{~m}^{2}$, which means 100 persons were evenly distributed on a floor of $900 \mathrm{~m}^{2}$. The first case was simulated by assuming that 100 persons were on the top floor and none were on the ground floor (case A, Table 1). All the other simulations were started with 100 persons on each floor (cases B-O). The simulations (a) are for cases where there is only one exit, and the staircase is in the center or halfway between the exit and the center.

The objective of each simulation of the evacuation from the building was to determine the time $(t)$ needed for complete evacuation. Numerous simulations were conducted systematically in order to determine the effect of the geometry of the building on the total evacuation time. To generate greater confidence in the numerical results, the simulations were conducted with two different numerical codes, Simulex [15] and FDS + Evac [32,33].

Simulex is a computer package for simulating the occupant evacuation movement in various types of large and geometrically complex building. Computer-aided-designed floor plans with staircases and exits defined are used. Based on distance maps using the $0.2 \mathrm{~m} \times 0.2 \mathrm{~m}$ spatial meshes, the distances of occupants to the nearest exit are calculated by default, route analysis is carried out and the total evacuation time can be predicted. The occupants who move toward the exits with individual characteristics such as walking speeds and the proximity of other people can be placed individually or in groups over the defined areas. The algorithms for the individual movement are based on real human behavior and data collected from video analysis of each person moving in crowds.

The FDS + Evac model is also used to simulate the evacuation of the occupants. The software considered each occupant as an individual agent, which is modeled as three elastic circles that represent the shape of human body. These agents are moving in a two dimensional plane representing the floors of the building. The shape of the agent is similar to the one used in Simulex. The agents are treated as autonomous bodies with their own physical properties and escape decisions. The contact forces, torques, psychological and motive forces of the agents are also included in the equations of motion of individual agents to simulate their movement. To ensure the agents move toward the exits, a walking direction vector field is generated first. This vector field is obtained by solving a two dimensional potential flow problem for incompressible fluid with all boundary conditions (walls, openings) specified. The movement algorithm includes many factors concerning the agents such as body sizes, the mass, the walking speed, and the moment of inertia. In addition to these physical factors, the social forces and the contact forces are also considered.

For each of the configurations of Fig. 2 we conducted additional simulations while averaging the evacuation time over the number of simulations. For example, if the number of simulations was $n$, then the evacuation time $\bar{t}$ reported in Table 1 is the average of the evacuation times produced by the $n$ simulations, namely $t_{1}, t_{2}, \ldots, t_{n}$. As shown in Fig. 3 , the average evacuation time $\bar{t}$ and the standard deviation $\sigma$ become insensitive to adding more simulations to the calculation when $n$ is approximately 30 , while the standard deviation of $\bar{t}_{i}$ relative to $\bar{t}$ also approaches a constant value. All the $\bar{t}$ values reported in Table 1 were calculated by performing 30 simulations of the same evacuation scenario.

The evacuation times and the geometric configurations considered are summarized in Table 1 . The effect of the shape of the floor area $(W / L)$ is shown in Fig. 4 . We find that there is a floor shape in the vicinity of $W / L \cong 2.78$ such that the total time needed for evacuation is minimum. This agrees approximately with Eq. (6). Two staircase positions were considered: in the center of the $W \times L$ floor, and half way between the centers and the $W$ side. Fig. 4 also shows that the trends are similar when the staircase is in the center of the floor and closer to the side. 
Table 1

Total evacuation time simulated numerically for evacuation from the inhabited space defined in Fig. 2, where there are two exits. The total number of occupants is 200, except in cases A and AG.

\begin{tabular}{|c|c|c|c|c|c|c|c|c|}
\hline \multirow[t]{2}{*}{ Case } & \multirow[t]{2}{*}{$L(\mathrm{~m})$} & \multirow[t]{2}{*}{$W(\mathrm{~m})$} & \multirow[t]{2}{*}{ Staircase position } & \multicolumn{2}{|c|}{ Number of people } & \multicolumn{3}{|l|}{$\bar{t}(\mathrm{~s})$} \\
\hline & & & & Ground & Upper floor & Simulex & FDS + Evac & (a) Simulex \\
\hline A & 30 & 30 & Center & 0 & 100 & 65.3 & 57.0 & 93.0 \\
\hline$A G$ & 30 & 30 & Center & 100 & 0 & 20.2 & 27.3 & 30.8 \\
\hline B & 30 & 30 & Center & 100 & 100 & 65.9 & 54.6 & 93.7 \\
\hline$C$ & 30 & 30 & Side & 100 & 100 & 84.8 & 58.5 & 89.1 \\
\hline $\mathrm{D}$ & 45 & 20 & Center & 100 & 100 & 85.8 & 61.2 & 102.5 \\
\hline $\mathrm{E}$ & 20 & 45 & Center & 100 & 100 & 62.6 & 52.3 & 91.6 \\
\hline $\mathrm{F}$ & 45 & 20 & Side & 100 & 100 & 90.7 & 61.0 & 94.1 \\
\hline G & 20 & 45 & Side & 100 & 100 & 84.3 & 54.0 & 86.2 \\
\hline $\mathrm{H}$ & 15 & 60 & Center & 100 & 100 & 79.8 & 57.4 & 86.9 \\
\hline I & 15 & 60 & Side & 100 & 100 & 87.5 & 71.4 & 98.5 \\
\hline $\mathrm{J}$ & 22.5 & 40 & Center & 100 & 100 & 64.0 & 53.1 & 91.6 \\
\hline $\mathrm{K}$ & 22.5 & 40 & Side & 100 & 100 & 84.6 & 61.6 & 84.7 \\
\hline $\mathrm{L}$ & 18 & 50 & Center & 100 & 100 & 60.9 & 55.9 & 88.0 \\
\hline M & 18 & 50 & Side & 100 & 100 & 84.1 & 54.5 & 88.9 \\
\hline $\mathrm{N}$ & 16 & 56.25 & Center & 100 & 100 & 61.8 & 56.8 & 88.3 \\
\hline 0 & 16 & 56.25 & Side & 100 & 100 & 85.7 & 59.3 & 95.7 \\
\hline
\end{tabular}
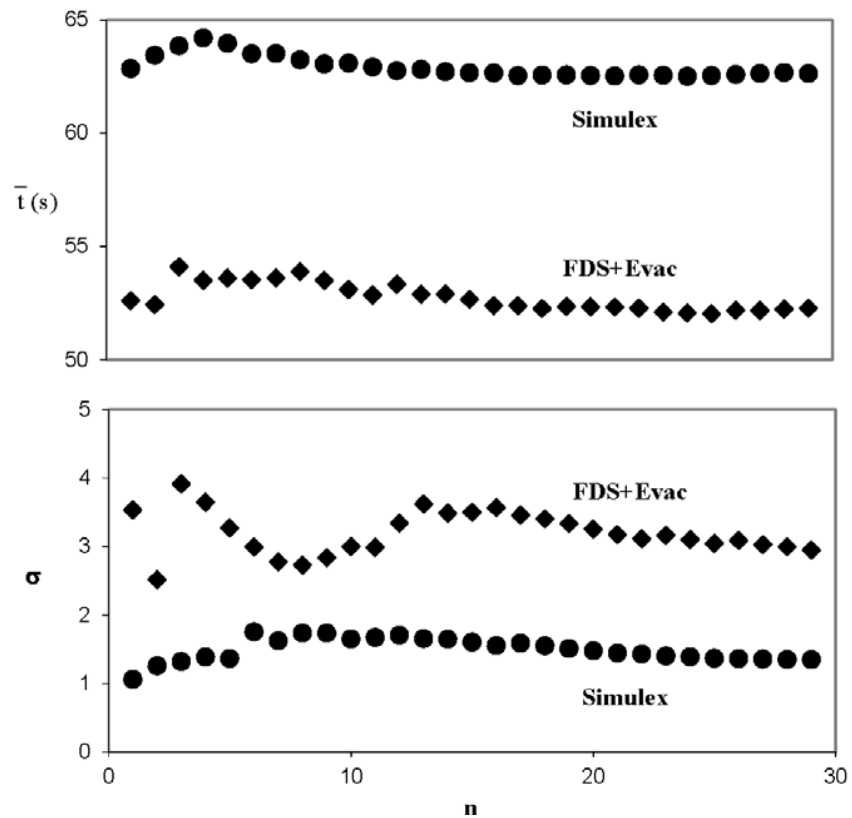

Fig. 3. The effect of the number of simulations $(n)$ on the averaged total evacuation time $(\bar{t})$ and the standard deviation $(\sigma)$.

Yet the evacuation time through the two exits is longer when the staircase is off center. This may be due to the larger distance that the users need to walk on the upper floor in order to reach the staircase. Another reason is that when the staircase is closer to one exit on the ground floor, people from upstairs have the tendency to choose mainly this exit. This may lead to congestion and a slowdown of the movement.

Fig. 5 shows that the trends uncovered with the two numerical codes are similar. In the cases reported in this figure, such as $\mathrm{B}, \mathrm{D}$ and $\mathrm{E}$, the staircase is located in the center of the floor area. The difference between the evacuation times calculated with Simulex and FDS + Evac is less than $28.7 \%$.

Cases A and B of Table 1 show that the evacuation time is not affected significantly by the presence of people on the ground floor. The total evacuation time is controlled by the group that is situated the farthest from the exits, namely, the 100 people located initially on the upper floor.

A new case $\left(\mathrm{F}^{\prime}\right)$ was defined by using the same parameters as in case $\mathrm{F}$ but placing the exits on the upper floor. In other words, in case $\mathrm{F}^{\prime}$ the lower floor is underground. The evacuation time calculated with Simulex for case $\mathrm{F}^{\prime}$ has the same value as for case F, and this means that the Simulex code does not account for the difference in pedestrian speed upward vs. downward on the staircase.

When the staircase is closer to one side, the Simulex code directs all the pedestrians toward the nearer of the two exits. This result called for simulations which are presented in Fig. 6 . The staircase is off center and the ground floor has either 


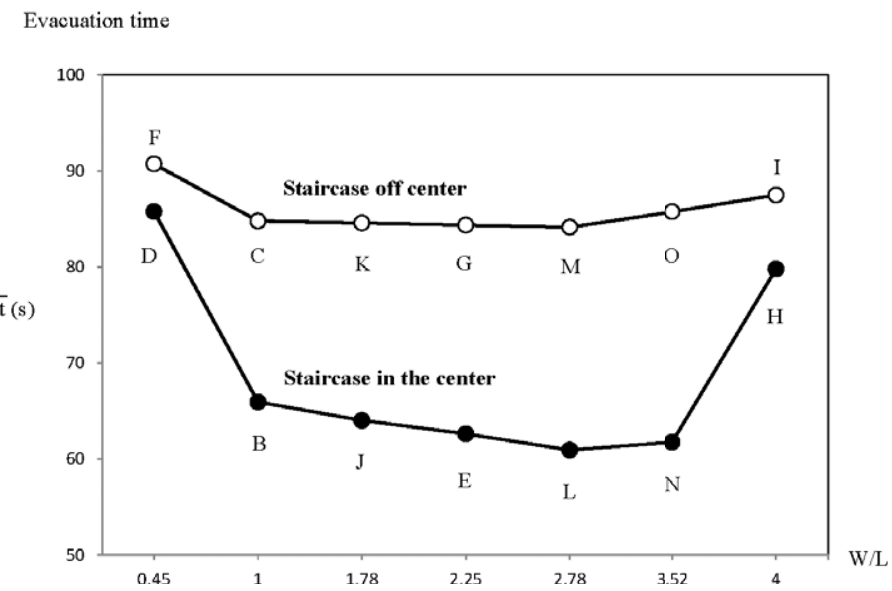

Fig. 4. The effect of the shape of the floor area on the evacuation time, showing also the effect of the location of the staircase.

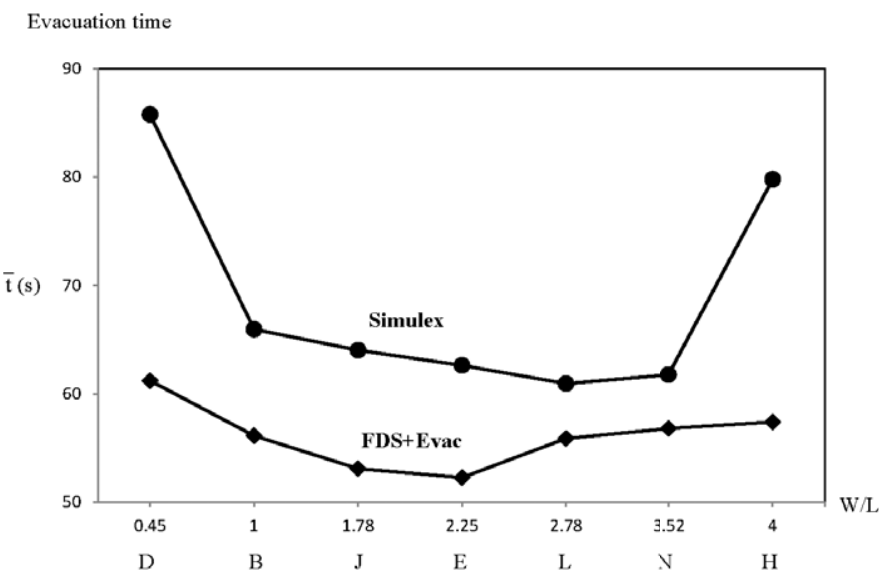

Fig. 5. Comparison of the evacuation times calculated with the two numerical codes.

Table 2

Total evacuation times when the total number of occupants is 400 .

\begin{tabular}{|c|c|c|c|c|c|c|}
\hline \multirow[t]{2}{*}{ Case } & \multirow[t]{2}{*}{$L(\mathrm{~m})$} & \multirow[t]{2}{*}{$W(\mathrm{~m})$} & \multirow[t]{2}{*}{ Staircase position } & \multicolumn{2}{|c|}{ Number of people } & \multirow{2}{*}{$\begin{array}{l}\bar{t}(\mathrm{~s}) \\
\text { Simulex }\end{array}$} \\
\hline & & & & Ground & Upper floor & \\
\hline B (400) & 30 & 30 & Center & 200 & 200 & 104.6 \\
\hline$C(400)$ & 30 & 30 & Side & 200 & 200 & 151.0 \\
\hline $\mathrm{D}(400)$ & 45 & 20 & Center & 200 & 200 & 127.9 \\
\hline$F(400)$ & 45 & 20 & Side & 200 & 200 & 155.3 \\
\hline $\mathrm{H}(400)$ & 15 & 60 & Center & 200 & 200 & 128.2 \\
\hline I (400) & 15 & 60 & Side & 200 & 200 & 165.6 \\
\hline $\mathrm{L}(400)$ & 18 & 50 & Center & 200 & 200 & 99.9 \\
\hline $\mathrm{M}(400)$ & 18 & 50 & Side & 200 & 200 & 153.6 \\
\hline $\mathrm{N}(400)$ & 16 & 56.25 & Center & 200 & 200 & 101.8 \\
\hline$O(400)$ & 16 & 56.25 & Side & 200 & 200 & 163.1 \\
\hline
\end{tabular}

two exits as in Fig. 2 or only one, which is located closest to the staircase. Fig. 6 shows that when the two exits are kept the evacuation time is always lower even though most users from upstairs tend to use the exit closer to the staircase. Yet, when the aspect ratio is 1.78 , the evacuation time in the case of one exit reaches a minimum corresponding to the case with two exits. This is an important result from a design point of view especially thinking of the economic aspect of construction.

The effect of placing all the pedestrians initially on the upper floor or the ground floor is made evident by cases A and AG in Table 1. When all the people are initially on the ground floor, the evacuation time is one third of when the people originate from the upper floor.

The evacuation time is longer when the number of people to be evacuated is greater. This effect is documented in the cases shown in Table 2, where the number of people on one floor was increased to 200. 

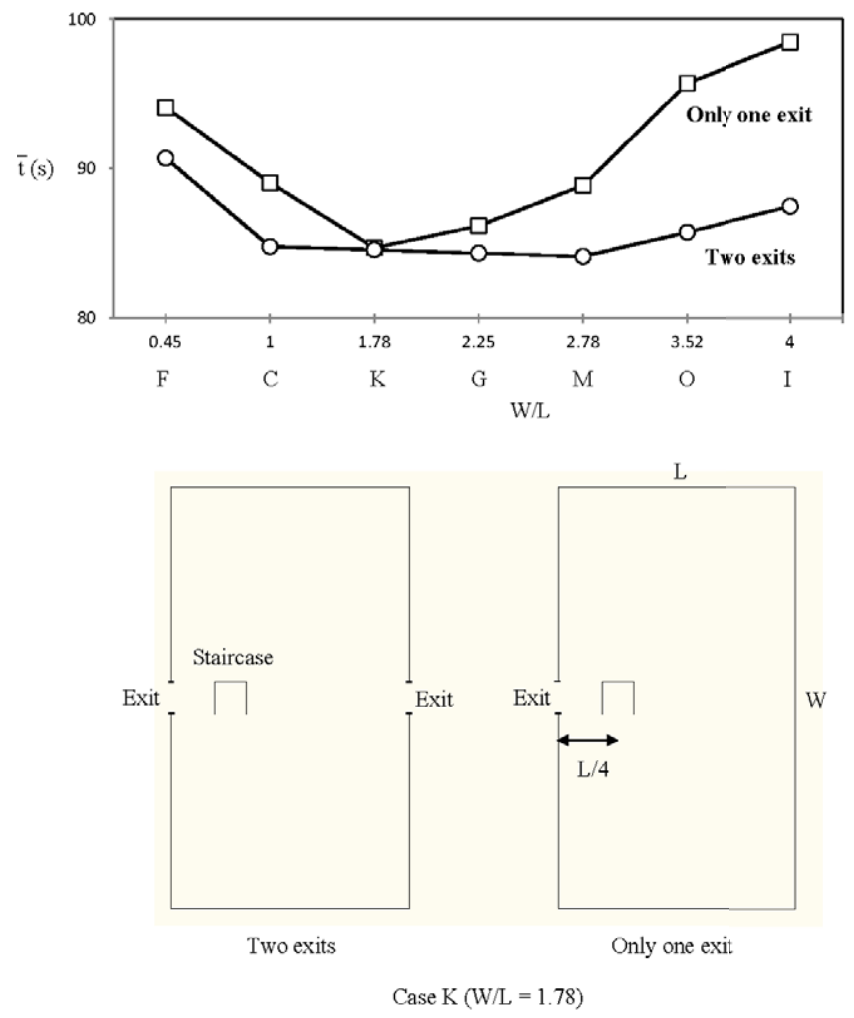

Fig. 6. The effect of staircase off center + one exit vs. two exits.

Fig. 7 shows the evacuation time through the two exits is shorter when the staircase is in the center of the floor. When two exits are allowed, users on both floors tend to evacuate evenly. When only one exit is provided, queuing up and congestion will occur at that exit and the evacuation process will be delayed.

Fig. 8 shows that longer evacuation time is needed for 400 people to evacuate in plans with staircase off center than that in the center. The trend is similar to the evacuation time of 200 people as shown in Fig. 4.

Finally, we considered the effect of the shape of the building profile $(H / L)$ on the total evacuation time. The volume of the building was fixed, $B=L^{2} H=2700 \mathrm{~m}^{3}$, and the slenderness ratio $H / L$ varied such that the square floor area decreased as the height $H$ increased.

The evacuation time was monitored by simulating the movement of people only on the top and ground floors. The density of people was fixed at one person per $9 \mathrm{~m}^{2}$ of floor area, according to the Code of Practice for Fire Safety in Buildings 2011 (Buildings Department, Hong Kong) [34].

The main results are reported in Table 3 and Fig. 9. Fig. 9(a) corresponds to the case with a square floor area, while the results for a rectangular floor area are presented in Fig. 9(b) and Table 4. In both cases, an optimum vertical aspect ratio exists leading to a minimum evacuation time. The optimal $H / L$ is higher when the simulations are performed with FDS + Evac. The difference lies in the modeling of the staircases: in Simulex the staircase is modeled as an inclined plane, while in FDS + Evac the staircases are made of two parts between each floor leading to a higher vertical evacuation time compared to the other software accounting for a direct staircase path and therefore a lower vertical evacuation time. This is in good agreement with Eq. (12) for a square floor shape, and Eq. (16) for a rectangular floor shape.

Table 3

Total evacuation time simulated numerically for evacuation from a building with fixed volume, varying height and varying (square) floor area.

\begin{tabular}{|c|c|c|c|c|c|c|c|c|}
\hline \multirow[t]{2}{*}{ Case } & \multirow[t]{2}{*}{ Floors } & \multirow[t]{2}{*}{$H(\mathrm{~m})$} & \multirow[t]{2}{*}{$L=W(\mathrm{~m})$} & \multirow[t]{2}{*}{$H / L$} & \multicolumn{2}{|c|}{ Number of people } & \multicolumn{2}{|l|}{$\bar{t}(\mathrm{~s})$} \\
\hline & & & & & Ground & Upper floor & Simulex & FDS + Evac \\
\hline 1 & 1 & 3 & 30 & 0.1 & 100 & 100 & 65.9 & 137 \\
\hline 2 & 2 & 6 & 21.21 & 0.28 & 50 & 50 & 54.2 & 132.6 \\
\hline 3 & 3 & 9 & 17.32 & 0.52 & 34 & 34 & 58.3 & 128.6 \\
\hline 4 & 4 & 12 & 15 & 0.8 & 25 & 25 & 66.6 & 96.3 \\
\hline 5 & 5 & 15 & 13.42 & 1.12 & 20 & 20 & 82 & 103.8 \\
\hline 6 & 6 & 18 & 12.25 & 1.47 & 17 & 17 & 92.6 & 106.5 \\
\hline 7 & 9 & 27 & 10 & 2.7 & 12 & 12 & 123.9 & 111.6 \\
\hline
\end{tabular}


Table 4

Total evacuation time simulated numerically for evacuation from a building with fixed volume, varying height and varying $\left(W=3^{1 / 2} L\right)$ floor area.

\begin{tabular}{|c|c|c|c|c|c|c|c|c|c|}
\hline \multirow[t]{2}{*}{ Case } & \multirow[t]{2}{*}{ Floors } & \multirow[t]{2}{*}{$H(\mathrm{~m})$} & \multirow[t]{2}{*}{$L(\mathrm{~m})$} & \multirow[t]{2}{*}{$\left(W=3^{1 / 2} L\right)(\mathrm{m})$} & \multirow[t]{2}{*}{$H / L$} & \multicolumn{2}{|c|}{ Number of people } & \multicolumn{2}{|l|}{$\bar{t}(\mathrm{~s})$} \\
\hline & & & & & & Ground & Upper floor & Simulex & $\overline{\text { FDS + Evac }}$ \\
\hline $1^{\prime}$ & 1 & 3 & 22.8 & 39.5 & 0.13 & 100 & 100 & 65.0 & 187.8 \\
\hline $2^{\prime}$ & 2 & 6 & 16.1 & 27.9 & 0.37 & 50 & 50 & 58.0 & 159.0 \\
\hline $3^{\prime}$ & 3 & 9 & 13.2 & 22.8 & 0.68 & 34 & 34 & 56.4 & 121.0 \\
\hline $4^{\prime}$ & 4 & 12 & 11.4 & 19.7 & 1.05 & 25 & 25 & 71.9 & 111.6 \\
\hline $5^{\prime}$ & 5 & 15 & 10.2 & 17.7 & 1.47 & 20 & 20 & 80.9 & 91.6 \\
\hline $6^{\prime}$ & 6 & 18 & 9.3 & 16.1 & 1.93 & 17 & 17 & 87.0 & 96.7 \\
\hline $7^{\prime}$ & 9 & 27 & 7.6 & 13.2 & 3.55 & 12 & 12 & 123.7 & 110.5 \\
\hline
\end{tabular}
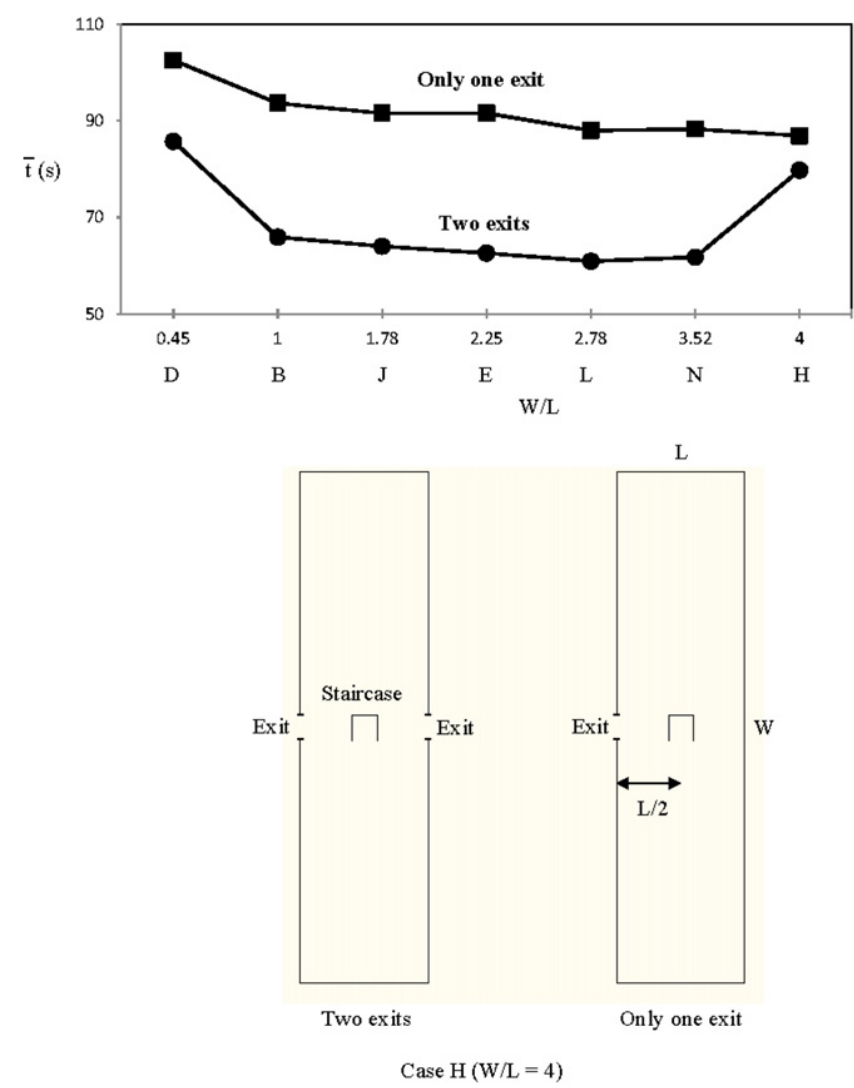

Fig. 7. The effect of staircase in the center + one exit vs. two exits.

Both FDS + Evac and Simulex are modeling human egress as a stochastic process. The setting of the parameters of the simulation models FDS + Evac and Simulex includes the number of floors, building height, the aspect ratio of the floors, and the number of people on each floor. For FDS + Evac, the social force model developed by Helbing's group is used to keep reasonable distances to walls and other agents. The following input data are required to run the FDS + Evac model: building dimension, exit dimension and locations, the evacuation grid size, simulation time, and time step. For Simulex, it is a ball bearing model that uses the fine network approach to calculate the evacuation path and evacuation time. Users of Simulex have to input the building layout plan and the location of the occupants, and number of occupants. The two models give similar simulation results for scenarios having one floor. In the current paper, vertical movement of the occupants has to be simulated and the modeling of staircases in these two models is different. Therefore, significant differences of evacuation time between the FDS + Evac and Simulex exist. Though the results are different, both results showed that there exists an optimum evacuation time.

\section{Concluding remarks}

There is a fundamental relationship between the geometric features (shape, structure) of an inhabited space and the time necessary to evacuate all the inhabitants in case of emergency. In this paper we demonstrated this fundamental aspect by analyzing the evacuation process as the physical flow of people from a three-dimensional enclosure to one or two exits at ground level (Fig. 1). 


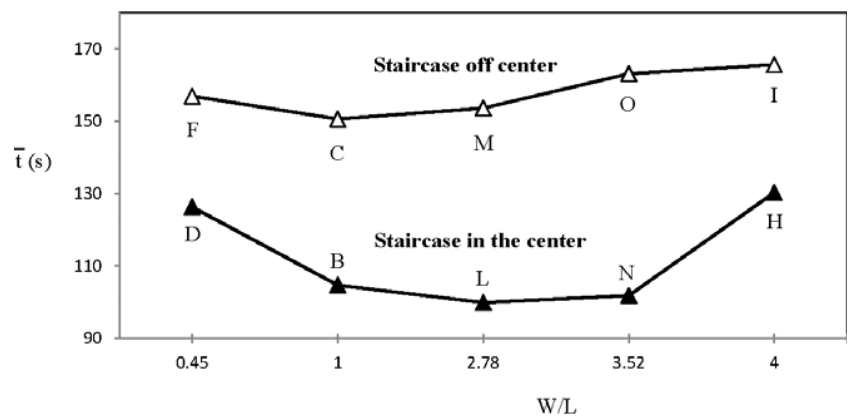

Fig. 8. The effect of 400 people + two exits (staircase off center vs. staircase in the center).
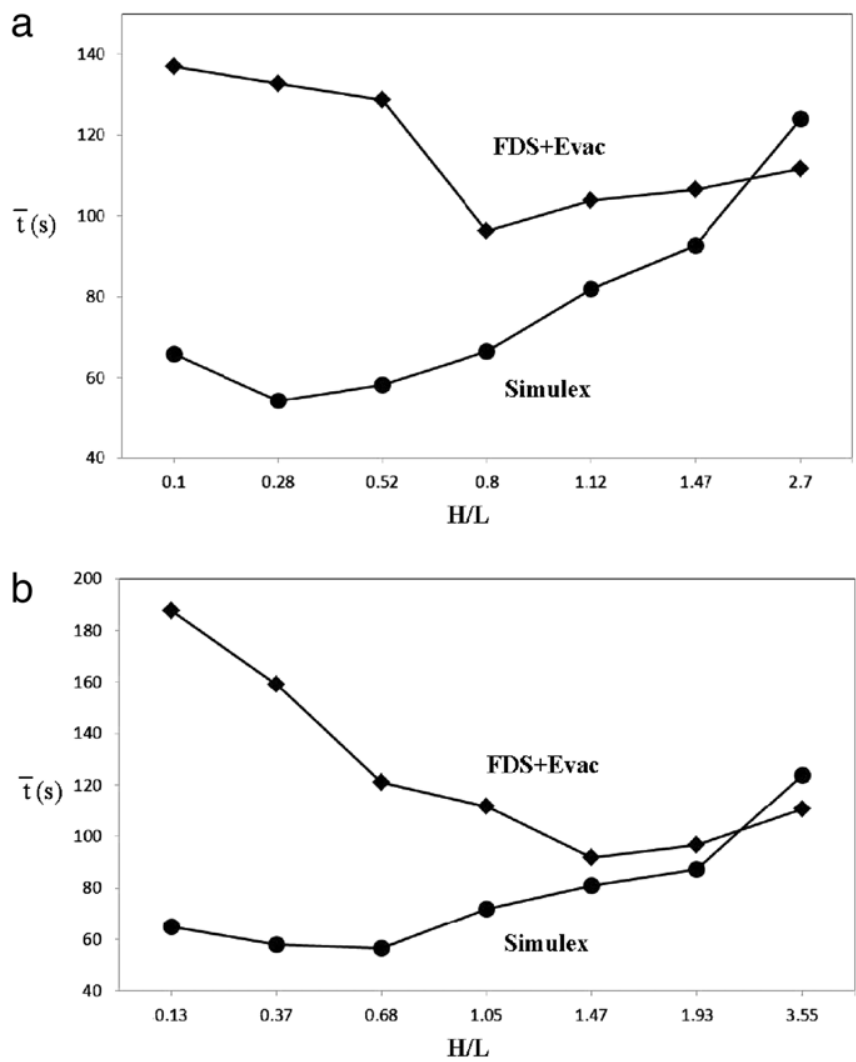

Fig. 9. The effect of the building profile on the total evacuation time: (a) $W / L=1$, (b) $W / L=3^{1 / 2}$.

First, we showed that the flow architecture has two aspect ratios that act as degrees of freedom, the floor shape $(W / L)$ and the profile shape $(H / L$, or $H / W)$. Next, we showed analytically that the total evacuation time exhibits clear minima with respect to both aspect ratios. The optimal floor and profile shapes, and the minimum evacuation times were derived. Finally, the predicted optimal shapes for minimum evacuation time were tested by means of numerical experiments based on numerous simulations of pedestrian movement from buildings with varying floor shapes and profile shapes. The numerical results confirmed the theoretical predictions. Furthermore, the validity of the numerical results was verified by conducting the numerical simulations with two different codes for simulating pedestrian movement.

The theoretical and experimental results suggest that the principle explored in this paper can be used for the purpose of configuring living spaces in ways that facilitate the evacuation of all the inhabitants in case of urgent need. The principle is the tight relationship between pedestrian safety and design, i.e., between the evacuation time and the configuration of the flow system (floor shape, number of floors, building height, staircase and elevator height and location, and the location of exits).

On the practical design side, we showed that it is useful to model the evacuating inhabitants as a physical flow system, as the inhabitants are not always in extreme forms of competitive behavior during evacuation. Based on the study by Chertkoff and Kushigian [35] extreme forms of competitive behavior will occur if the following factors appear in combination: severe 
limitation of passage space, high occupant load density, widespread lack of knowledge about the paths and exits, lack of an adequate emergency plan, widespread perception of serious negative consequences such as failure to reach the place of safety, widespread perception of a severe limitation of egress time, strong response tendency to use the most familiar route, an inability of potential leaders and failure to keep the exterior opening clear.

In modern building design, the above factors are considered in the building design and construction stage. The available safe egress time (ASET) and the required safe egress time (RSET) are considered prior to the building construction. ASET is the time from ignition to the untenable room condition due to fire. RSET can be estimated using the detection time, alarm time, pre-movement time (including the responder time, recognition time, path finding time) and the traveling time to the place of safety. To ensure that the RSET is shorter than the ASET, various fire safety measures are provided. These include occupant load control, sufficient number of exits, adequate means of escape, use of detection and alarm system, public addressing system, clear directional sign, exit sign, smoke control system and fire safety management plan. These measures can eliminate the factors leading to the panic and the extreme forms of competitive behavior. Therefore, the major impact needed to be considered in the calculation of RSET is the influence of the building layout and geometry on the evacuation time. The model in this paper assumes that the detection time, alarm time and pre-movement time are the same and not significant for all the simulation scenarios, and the total evacuation time is equal to the traveling time. Trial and error has to be used to determine the optimal evacuation time due to the impact of building configuration. With constructal theory, the impact of the building geometry on evacuation time can be determined prior to the simulation work.

\section{Acknowledgment}

Prof. Bejan's research is supported by the US National Science Foundation award no. 1347188.

\section{References}

[1] A. Bejan, S. Lorente, Constructal law of design and evolution: physics, biology, technology, and society, J. Appl. Phys. 113 (2013) 151301.

[2] A. Bejan, S. Lorente, The constructal law and the evolution of design in nature, Phys. Life Rev. 8 (2011) 209-240.

[3] A. Bejan, G.A. Ledezma, Streets, tree networks and urban growth: optimal geometry for quickest access between a finite-size volume and one point, Physica A 255 (1998) 211-217.

[4] A.F. Miguel, A. Bejan, The principle that generates dissimilar patterns inside aggregates of organisms, Physica A 388 (2009) 727-731.

[5] R.G. Kasimova, D. Tishin, A.R. Kacimov, Streets and pedestrian trajectories in an urban district: Bejan's constructal principle revisited, Physica A 410 (2014) 601-608.

[6] A.F. Miguel, The emergence of design in pedestrian dynamics: locomotion, self-organization, walking paths and constructal law, Phys. Life Rev. 10 (2013) $168-190$.

[7] J.M.P.Q. Delgado, The constructal law: from man-made flow systems to pedestrian flows, Phys. Life Rev. 10 (2013) 197-198

[8] A. Bejan, G.W. Merkx (Eds.), Constructal Theory of Social Dynamics, Springer, New York, 2007.

[9] X. Zheng, T. Zhong, M. Liu, Modeling crowd evacuation of a building based on seven methodological approaches, Build. Environ. 44 (2009) 437-445.

[10] J. Hu, L. You, J. Wei, M. Gu, Y. Liang, The effects of group and position vacancy on pedestrian evacuation flow model, Phys. Lett. A 378 (2014) $1913-1918$.

[11] J. Um, S.-W. Son, S.-Ik Lee, H. Jeong, B.J. Kim, Scaling laws between populations and facility densities, PNAS 106 (2009) 14236-14240. http://dx.doi. org/10.1073/pnas.0901898106.

[12] L.E. Mavromatidis, A. Mavromatidi, H. Lequay, The unbearable lightness of expertness or space creation in the "climate change" era: a theoretical extension of the "constructal law" for building and urban design, City Cult. Soc. (2014) http://dx.doi.org/10.1016/j.ccs.2014.09.003.

[13] S. Salat, L. Bourdic, Urban complexity, efficiency and resilience, in: Z. Morvaj (Ed.), Efficiency-a Bridge to Low Carbon Economy, InTech, ISBN: 978953-51-0340-0, 2012.

[14] R.A. Smith, J.F. Dickie, Engineering for Crowd Safety, Elsevier, Amsterdam, 1993.

[15] P.A. Thompson, E.W. Marchant, A computer model for the evacuation of large building populations, Fire Saf. J. 24 (1995) 131-148.

[16] J.J. Fruin, Pedestrian Planning and Design, Metropolitan Association of Urban Designer and Environmental Planners, Inc., New York, 1971.

[17] M. Moussaid, D. Helbing, G. Theraulaz, How simple rules determine pedestrian behaviour and crowd disaster, PNAS 108 (2011) 6884-6888.

[18] D.R. Parisi, S.A. Soria, R. Josens, Faster-is-slower effect in escaping ants revisited: ants do not behave like humans, Saf. Sci. 72 (2015) $274-282$. http://dx.doi.org/10.1016/j.ssci.2014.09.014.

[19] J. Li, W.K. Chow, Numerical studies on evacuation pattern in a lecture hall, J. Appl. Fire Sci. 10 (2000-2001) 265-276.

[20] J. Pauls, Proceedings of 6th International Fire Protection Engineering Seminar, Karlsruhe, Germany, 1982, pp. 295-306.

[21] J. Pauls, The movement of people in building and design solutions for means of egress, Fire Technol. 20 (1984) 27-47.

[22] A. Polus, J.L. Schofer, A. Ushpiz, Pedestrian flow and level of service, J. Transp. Eng. 109 (1983) 46-56.

[23] K. Ando, H. Ota, T. Oki, Forecasting the flow of people, Railway Res. Rev. 45 (1988) 8-14. (in Japanese).

[24] R.A. Smith, Density, velocity and flow relationships for closely packed crowd, Saf. Sci. 18 (1995) 321-327.

[25] M.D. Annesley, A. Beswick, P. Buchanan, Development and application of pedestrian assignment models in London railway station studies, Traffic Eng. Control 30 (1989) 345-352.

[26] V.M. Predtechenskii, A.I. Milinskii, Planning for Foot Traffic Flow in Buildings, Amerind Publishing Company, Inc., New Delhi, 1978, (translated from Russian, 1969).

[27] P.N. Daly, F. McGrath, T.J. Annesley, Pedestrian speed/flow relationships for ground stations, Traffic Eng. Control 32 (1991) 75-78.

[28] H.E. Nelson, F.W. Mowrer, Emergency movement, in: P.J. DiNenno (Ed.), SFPE Handbook of Fire Protection Engineering, second ed., National Fire Protection Association, Quincy, Massachusetts, 1995, pp. 286-295.

[29] G. Proulx, Evacuation time and movement in apartment buildings, Fire Saf. J. 24 (1995) 229-246.

[30] Guide to Safety at Sports Ground, fourth ed., HMSO, London, 1997.

[31] National Fire Protection Association, NFPA 130: Standard for Fixed Guideway Transit and Passenger Rail Systems, NFPA, Quincy, Massachusetts, 2007.

[32] T. Korhonen, S. Hostikka, Fire dynamics simulator with evacuation: FDS+Evac. Technical Reference and User's Guide, VTT Working Papers 119, VTT Technical Research Centre of Finland, 2009

[33] T. Korhonen, S. Hostikka, S. Heliovaara, H. Ehtamo, FDS+Evac: an agent based fire evacuation model, in: W.W.F. Klingsch, et al. (Eds.), Pedestrian and Evacuation Dynamics 2008, 2008, pp. 109-120.

[34] Code of Practice for Fire Safety in Buildings 2011, Buildings Department, Hong Kong, 2012.

[35] J.M. Chertkoff, R.H. Kushigian, The Psychology of Emergency Egress and Ingress, Praeger Publishers, Westport, CT, 1999. 